\title{
Crowding Out in Blood Donation: Was Titmuss Right?
}

Carl Mellström, Department of Economics, Gothenburg University, Box 640, SE-450 30 Gothenburg, Sweden; e-mail: carl.mellstrom@economics.gu.se

Magnus Johannesson, Department of Economics, Stockholm School of Economics, Box 6501, SE-113 83 Stockholm, Sweden; e-mail: magnus.johannesson@hhs.se

\begin{abstract}
In his seminal 1970 book, The Gift Relationship, Richard Titmuss argued that monetary compensation for donating blood might crowd out the supply of blood donors. To test this claim we carry out a field experiment with three different treatments. In the first treatment subjects are given the opportunity to become blood donors without any compensation. In the second treatment subjects receive a payment of SEK 50 (about \$7) for becoming blood donors, and in the third treatment subjects can choose between a SEK 50 payment and donating SEK 50 to charity. The results differ markedly between men and women. For men the supply of blood donors is not significantly different among the three experimental groups. For women there is a significant crowding out effect. The supply of blood donors decreases by almost half when a monetary payment is introduced. There is also a significant effect of allowing individuals to donate the payment to charity, and this effect fully counteracts the crowding out effect.
\end{abstract}

Jel Classification: C93, D64, I18, Z13.

Key words: Crowding out, monetary incentives, field experiments, altruism.

Acknowledgements: It would have been impossible to carry out this study without the help of Ulla Britt Frank, Carina Ljungvall and Åsa Nilsson and the other members of the staff at the Regional Blood Center at Sahlgrenska University Hospital. We are also grateful to Martin Dufwenberg, Uri Gneezy, Peter Martinsson, two anonymous referees and seminar participants at Gothenburg University and the iHEA meeting in Barcelona for helpful comments and to Hannah Ajell, Anders Boman, Matilda Orth and Sven Tengstam for research assistance. Finally, we thank the Jan Wallander and Tom Hedelius Foundation and the Swedish Research Council for financial support. 


\section{INTRODUCTION}

In his seminal 1970 book, The Gift Relationship, Richard Titmuss argued that monetary compensation for donating blood might reduce the supply of blood donors (Titmuss 1970). This hypothesis, often referred to as “crowding out,” was initially met with skepticism among economists (Solow 1971; Arrow 1972).

The idea that economic incentives may sometimes backfire has, however, received some support in recent years. Building on work in social psychology, Frey and Oberholzer (1997) argued that the introduction of monetary payments may reduce the intrinsic motivation to behave altruistically or perform one's civic duty. ${ }^{1}$ They illustrated this with questionnaire data about the location of a nuclear waste repository facility, showing that individuals were less willing to accept locating the facility in their community if they were offered monetary compensation.

A growing experimental literature testing monetary incentives also suggests that financial incentives can be counterproductive. Gneezy and Rustichini (2000a) found that subjects answered fewer questions correctly on an IQ test if they were paid a small fee per correct answer, and that high school students in Israel collected less money towards charity if they were offered a small monetary incentive. ${ }^{2}$ In a field experiment on day-care centers in

\footnotetext{
${ }^{1}$ See also the related papers by Frey $(1993,1994)$ and Frey et al. (1996). See Lepper and Greene (1978) and Deci and Ryan (1985) for overviews of the literature on intrinsic motivation in social psychology.

2 The Gneezy and Rustichini study (2000) also suggested that if the monetary incentive is raised further performance will improve. This is in contrast to the Frey and Oberholzer (1997) study, which found that the amount of compensation had no significant effect on the acceptance of the nuclear waste repository facility.
} 
Israel, Gneezy and Rustichini (2000b) furthermore found that introducing a fine increased the number of late-coming parents. Consistent with this finding, several recent laboratory experiments suggest that the introduction of fines or minimum performance requirements can reduce performance (Fehr and Gächter, 2002; Fehr and Rockenbach, 2003; Fehr and List, 2004; Falk and Kosfeld, 2006).

Despite the increased interest in the crowding out hypothesis, the original claim by Titmuss (1970) about blood donations has never been tested empirically. ${ }^{3}$ The contribution of this study is threefold. Firstly, we provide a test of crowding out in blood donation. Secondly, we test an alternative incentive scheme that could potentially overcome the crowding out effect, if it exists. In this incentive scheme subjects are given the choice between a monetary compensation and donating the same amount to charity. Such an incentive scheme is for instance used by the Economic Journal for paying referees. From a theoretical perspective this incentive scheme can be motivated by the recent signaling model of crowding out of Bénabou and Tirole (2006). ${ }^{4}$ According to that model individuals engage in civic activities to signal altruism to receive social esteem. The introduction of monetary incentives may make signaling more difficult and thereby cause crowding out. A charity option on the other hand facilitates signaling, and the crowding out effect may therefore be counteracted.

\footnotetext{
${ }^{3}$ An exception to this is the questionnaire data collected by Ireland and Koch (1973). They asked a class of economics students if they would be willing to provide blood at various prices. Consistent with the crowding out hypothesis there was a reduction in the supply of blood donors at the first positive price.

${ }^{4}$ See also the related work of Ellingsen and Johannesson (2007), who similarly assume that individuals want to signal altruism to increase social esteem or prestige. Seabright (2004) also presents a signaling model of crowding out where individuals want to signal altruism to make them more attractive partners in a later matching stage.
} 
Thirdly, we test for gender differences in crowding out. There is an increasing literature on gender differences in behavior based on experimental data (see Croson and Gneezy (2004) for an overview of this literature). Stylized facts from this literature are that women appear to be more prosocial, more risk averse and more competitive than men. However, we are not aware of any tests of gender differences in crowding out of prosocial activities.

We carry out a field experiment where subjects are randomly divided into three groups. In the first treatment subjects are given the opportunity to become blood donors without any compensation. In the second treatment subjects are offered a SEK 50 (about US \$7) payment for becoming blood donors, and in the third treatment subjects can choose between a SEK 50 payment and donating SEK 50 to charity (The Swedish Children’s Cancer Foundation).

For the overall sample the supply of blood donors decreases from $43 \%$ to $33 \%$ when a payment is introduced consistent with a crowding out effect, but the effect is not statistically significant. We therefore cannot reject the null hypothesis of zero crowding out at conventional significance levels. The introduction of a charity option increases the supply of blood donors from $33 \%$ to $44 \%$, but also in this case we cannot statistically reject the null hypothesis of no effect.

However, the results differ markedly between men and women. For men there is no significant difference among the three experimental groups. For women there is a significant crowding out effect; the supply of blood donors decreases from $52 \%$ to $30 \%$ when a payment is introduced. There is also a significant effect of allowing subjects to donate the payment to charity, which fully counteracts the crowding out effect. Titmuss's original conjecture was silent about the effect of gender, but our results suggest that his conjecture holds for women but not for men. In terms of the recent signaling model of crowding out of Bénabou and 
Tirole (2006), the difference between men and women can be interpreted in terms of women being more concerned with social esteem than men. ${ }^{5}$

The design of the experiment is described below, followed by a presentation of the results. The paper ends with some concluding remarks.

\section{EXPERIMENTAL DESIGN}

\subsection{Procedure}

The study was carried out in collaboration with the Regional Blood Center, Sahlgrenska University Hospital in Gothenburg, Sweden. ${ }^{6}$ The Regional Blood Center is operated by the County Council, which is also responsible for providing health care to the Gothenburg County inhabitants. Blood donations in Sweden are based on a voluntary system, in which it is not allowed to pay monetary compensation to blood donors. Blood donors are asked to donate blood three or four times per year depending on gender.

To become a blood donor in Sweden it is necessary to first complete a health examination. The health examination consists of a health declaration and a physical examination by a nurse (a blood pressure measurement and a blood sample test). About one month after the health examination the candidates receive an answer about whether or not they are suitable as blood donors (and if they are suitable blood donors they are given a mutually convenient appointment time to donate blood). In the experiment subjects who have not previously donated blood are offered to carry out the health examination to become blood donors.

\footnotetext{
${ }^{5}$ This is also the interpretation of our results given by Bénabou and Tirole (2006, p. 1662).

${ }^{6}$ The study was approved by the Regional Ethical Committee in Gothenburg.
} 
Subjects arrive at a room and are given a general introduction about blood donation by a nurse from the Regional Blood Center, Sahlgrenska University Hospital. Thereafter the subjects are randomly allocated into the three groups, directed to three separate rooms (the three experimental treatments are further described below). Subjects are seated apart from each other and are told not to talk to each other. They are furthermore told to raise their hands if they have any questions, and that the questions will be answered privately. Each subject receives a questionnaire that he/she is asked to complete. The questionnaire consists of a few background questions and an offer to complete the health examination to become a blood donor. Those who answer no to the health examination question leave the room. Those who answer yes complete the health declaration in the room and are thereafter transported by bus to the blood donation unit at the Sahlgrenska University Hospital for the physical examination. After everyone has completed the physical examination they are transported back by bus to the campus where the experiment was conducted.

\subsection{Experimental treatments}

Three treatments are carried out. In the first treatment (the "no payment" treatment) subjects are not offered any compensation to complete the health examination. In the second treatment (the "SEK 50 payment" treatment) subjects are offered a SEK 50 compensation (about US \$7 at the time of the experiment) to complete the health examination. In the third treatment (the "SEK 50 payment with charity option" treatment) subjects can choose between receiving a SEK 50 payment and donating SEK 50 to charity (the Swedish Children's Cancer Foundation) if they complete the health examination. The phrasing of the "donation question" in each of the experimental groups is reproduced in the Appendix. 


\subsection{Subjects}

We carry out five sessions of the experiment. At each session the subjects are randomly divided among the three experimental treatments carried out in three separate rooms. Subjects receive a show-up fee consisting of two lottery tickets worth SEK 50 (about US \$7). All subjects are undergraduate students at Gothenburg University, but the student pool and the exact location of the experiment vary among the sessions. One session is carried out at the Sahlgrenska Academy (the medical school at Gothenburg University) with students in medicine (including dentistry and nursing students); two sessions are carried out at the School of Economics and Commercial Law with students in business, economics and commercial law; and two sessions are carried out at the Faculty of Education with students from the teacher training programme. The subjects were mainly recruited through class advertisements. In particular we targeted large classes where the experiment started immediately after the end of the class. For the first session (at the medical school) we also used e-mail advertisements and posters. In the recruitment and advertisements for the experiment we were obliged to inform subjects that the experiment was about attitudes toward blood donation, in order to get the study approved by the regional ethical committee (which has to approve all studies involving medical tests in Sweden). This may have led to a selection of subjects interested in this topic or contemplating giving blood (and also to a selection of pre-existing blood donors who were excluded from the study).

A problem in recruiting subjects is that the decision to carry out the health examination to become a blood donor is not relevant for some subjects. Three groups of subjects therefore had to be excluded. The first group was subjects who were already blood donors. The second group was subjects who had already undergone the health examination, but has not yet donated blood. The third group was subjects who were aware that they could not become 
blood donors, because they fulfilled some of the exclusion criteria. We did not want to state these exclusion criteria at the recruitment process, to avoid revealing the purpose of the experiment. We also did not want to screen out these subjects prior to filling out the questionnaire, as some other subjects may then also have opted to leave the experiment. These subjects were therefore excluded after filling out the questionnaire.

In the questionnaire we asked subjects if they had donated blood during the previous five years to identify the group of blood donors $(n=98)$. This group was surprisingly large, suggesting that the recruitment process led to a selection of subjects interested in blood donation. ${ }^{7}$ The second and third groups of subjects excluded from the study were identified in a follow-up question where subjects were asked to motivate their decision about undergoing the health examination. Seven subjects had previously carried out the health examination, but not yet donated blood. Fourteen subjects stated that they knew that they were unable to become blood donors due to exclusion criteria. ${ }^{8}$

This leaves a total sample size of 262 subjects for the analysis. In Table 1 we show the gender distribution and the distribution across subject pools in the three treatments. More

\footnotetext{
${ }^{7}$ These subjects were offered to make an additional blood donation at the hospital with the same incentive scheme as used in that treatment. However, 36 subjects had recently donated blood and were not eligible to donate again. Of the remaining 62 blood donors, 30 subjects made a blood donation.

${ }^{8}$ Six of these subjects explicitly stated that they had already carried out the health examination to become blood donors and were found to be unsuitable. The remaining eight subjects had the following exclusion criteria: several allergies (1 subject); previous hepatitis-B infection (1 subject); APC-resistence (1 subject); anemia (1 subject); previous blood transfusion (1 subject); takes medications that preclude donating blood (2 subjects); recently arrived from a tropical country (1 subject).
} 
women than men (153 versus 109) participated in the experiment. This is consistent with the gender distribution at Gothenburg University overall, where $67 \%$ of the students are women. Nearly half the subjects are from the School of Economics and Commercial Law, and more than a third of the subjects are from the Faculty of Education. The remaining 34 subjects are from the Sahlgrenska Academy. ${ }^{9}$ [insert Table 1 about here]

\section{HYPOTHESES AND TESTS}

Let $\mu_{1}, \mu_{2}$, and $\mu_{3}$ denote the fraction of subjects agreeing to become blood donors in treatments 1 (“No payment”), 2 (“SEK 50 payment”), and 3 (“SEK 50 payment with charity option”), respectively. We test two hypotheses, which are outlined below.

\subsection{Crowding out hypothesis}

Our first hypothesis to be tested is that the introduction of a monetary payment reduces the supply of blood donors: ${ }^{10}$

Hypothesis 1: The supply of blood donors is higher with no payment than with a payment, i.e. $\mu_{1}>\mu_{2}$

\footnotetext{
${ }^{9}$ The low number of subjects from the session at the Sahlgrenska Academy is explained by a high fraction of previous blood donors ( $\mathrm{n}=38$ ) among the medical students.

${ }^{10}$ Note that this is a conservative test of crowding out as the monetary payment should increase the supply of blood donors somewhat without a crowding out effect.
} 


\subsection{Charity option hypothesis}

Our second hypothesis to be tested is that the introduction of a charity option counteracts the crowding out effect. A counteracting effect implies that adding a charity option will increase the supply of blood donors:

Hypothesis 2: For a given monetary payment, the supply of blood donors is higher with a charity option than without a charity option, i.e. $\mu_{3}>\mu_{2}$.

\subsection{Statistics}

To compare the fraction of subjects agreeing to become blood donors among the treatments, we use a non-parametric contingency table Pearson chi-square test (D’Agostino et al., 1988). We also use logistic regression analysis of the decision to become a blood donor to test the hypotheses. In the logistic regression analysis we control for the subject affiliation and gender (gender was collected in the questionnaire). ${ }^{11}$ We present results for the entire sample, but also separately for men and women. We had no prior hypothesis concerning differences between men and women, and the study was not designed to test for gender differences as the statistical power to detect effects in specific subgroups like gender is limited. But gender differences have been observed in several other experiments (see the overviews in Camerer (2003) and Croson and Gneezy (2004)), and in the results we observed marked differences between men and women. All reported $p$-values are two sided.

\footnotetext{
${ }^{11}$ Instead of dummy variables for subject affiliation we also tested adding dummy variables for each session, but that led to very similar results and does not change any of the conclusions reported below.
} 


\section{RESULTS}

The experimental results are shown in Table 2. Without any payment, $43 \%$ of the subjects agree to become blood donors. With a payment of SEK 50 this fraction decreases to 33\%, consistent with the crowding out hypothesis. ${ }^{12}$ This difference is, however, not statistically significant and we cannot reject the null hypothesis of no difference. The fraction of blood donors increases to $44 \%$ when a charity option is added to the SEK 50 payment. This effect points towards a positive incentive effect of the charity option consistent with the charity option hypothesis, but again the effect fails to be statistically significant at conventional levels. Thus we cannot reject the null hypothesis of no difference. [insert Table 2 about here]

When we estimate separate results for men and women we can see that the results differ markedly. This is also illustrated in Figure 2. For men about a third of the subjects agree to become blood donors in each treatment, and there is no significant difference between the treatments. For women there is a sizeable crowding out effect. The supply of blood donors drop from 52\% to $30 \%$ when the SEK 50 payment is introduced. This effect is significant at the $5 \%$ level. When subjects have the option to donate the SEK 50 payment to charity, the crowding out effect is counteracted and the supply of blood donors is $53 \%$. This effect of the charity option is also significant at the $5 \%$ level. For women therefore we find support for the crowding out hypothesis and the charity option hypothesis. ${ }^{13}$ [insert Figure 2 about here]

\footnotetext{
${ }^{12}$ No subjects refused to take their reward in the SEK 50 payment group.

${ }^{13}$ We also tested if the fraction of subjects that agreed to become blood donors differed significantly between men and women at each treatment. Without any payment the difference between men and women is significant at the 5\% level (chi-square value=4.704; $p$ value=0.030). In the SEK 50 payment group the difference is not significant (chi-square
} 
For men 9 out of the 13 (69\%) blood donors in the charity option group donate the SEK 50 payment to charity. For women 20 out of 26 (77\%) subjects donate the SEK 50 payment to charity. The difference between men and women in the fraction of blood donors who donate the SEK 50 payment to charity is not significant ( $p$-value $=0.604$ according to a Pearson chisquare test).

In Table 3 we present the logistic regression results. In the regressions we control for the subject affiliation. The regression results confirm the non-parametric test results. When all subjects are included there is no significant difference among the experimental groups. The dummy variable for gender is significant at the $5 \%$ level, indicating that the fraction of blood donors is higher for women. As a test of whether the regression equations differ between men and women we add interaction terms between gender and all other variables. The interaction terms are jointly significant at the $1 \%$ level. $^{14}$

The separate regression equations for men and women are also shown in Table 3. In the Table we furthermore test if the individual regression coefficients differ significantly between men and women. ${ }^{15}$ For men there is no significant difference among the experimental groups. The subject population variables for men show that the fraction of blood donors is significantly lower at the Faculty of Education than at the Sahlgrenska Academy and the School of Economics and Commercial Law.

value $=0.476$; $p$-value $=0.490$ ); and in the charity donation group the difference is significant at the $10 \%$ level (chi-square value=3.425; $p$-value=0.064).

${ }^{14}$ The chi-square value of the likelihood ratio test was 19.622 (4 df), and the critical value at the $1 \%$ level is 13.28 .

15 This is identical to testing the significance of the interaction terms in the model with interaction terms between gender and all other variables. 
For women the dummy variable for the no payment treatment is significant at the $10 \%$ level ( $p$-value $=0.062$ ), consistent with a crowding out effect. The marginal effect is 20 percentage units. The dummy variable for the charity option treatment is significant at the $5 \%$ level, consistent with an increase in the supply of blood donors when subjects have the option to donate the payment to charity. The marginal effect is 23 percentage units. Both the coefficient of the no payment treatment and the coefficient of the charity option treatment differ significantly between men and women at the $10 \%$ level. ${ }^{16}$ The subject population variables for women show that the supply of blood donors is significantly lower at the School of Economics and Commercial Law and the Faculty of Education than at the Sahlgrenska Academy. [insert Table 3 here]

In Figures 2 and 3 we show the results for the three different subject populations. We did not have any strong a priori belief that the results would differ across the different subject groups, but this data was mainly collected to be able to control for this variable in the analyses. However, it is also interesting to investigate if the results are stable across the three

16 We also estimated a model with interactions between gender and the experimental treatments, but no interactions between gender and the subject group dummy variables (i.e. constraining the effects of the subject group dummy variables to be the same for men and women). This yielded very similar results: the no payment treatment for women is significant at the $10 \%$ level ( $p$-value $=0.055)$, and the charity option treatment for women is significant at the $5 \%$ level ( $p$-value $=0.031)$. The interaction between the no payment treatment and gender is significant at the $10 \%$ level ( $p$-value $=0.086$ ) and the interaction between gender and the charity option treatment is significant at the $10 \%$ level ( $p$-value $=0.073$ ). The gender dummy variable is not significant ( $p$-value $=0.587$ ) showing that there is no significant difference between men and women in the supply of blood donors in the SEK 50 payment treatment (the baseline category in the regression equation). 
subject groups. Figure 2 shows the results for men. For the biggest sample (the School of Economics and Commercial Law), the fraction of blood donors is about $40 \%$ in each treatment. At the Faculty of Education only two out of 32 subjects agree to become blood donors, and they are both in the SEK 50 payment group. There are only nine men from the Sahlgrenska Academy in the study, making it difficult to draw inferences about this group. ${ }^{17}$ [insert Figure 2 about here]

The results for women in the different subject pools are shown in Figure 3. The overall pattern for women with a crowding out effect and a positive effect of the charity option can be seen in all three subject populations. ${ }^{18}$ [insert Figure 3 about here]

As a sensitivity analysis we also removed all the subjects from the Sahlgrenska Academy from the analysis. The recruitment process for these subjects differed somewhat (posters and e-mail advertisements were used in addition to class advertisements), which may have led to a stronger selection towards subjects interested in blood donation. Excluding these subjects leads to similar results as in the baseline analysis. For men the fraction of blood donors is now $29 \%, 34 \%$, and $32 \%$ in the three experimental treatments, and the difference between treatments is not significant. For women the fraction of blood donors is now $48 \%$, $27 \%$, and $44 \%$ in the three experimental treatments. The crowding out effect is significant at

\footnotetext{
${ }^{17}$ For men there is no significant difference at the $10 \%$ level among the three treatments for any of the three subject populations.

${ }^{18}$ For women the crowding out effect and the effect of adding a charity option is significant at the $10 \%$ level among subjects at the School of Economics and Commercial Law ( $p$ value $=0.074$ in both cases). For subjects at the Faculty of Teaching these differences are not significant at the $10 \%$ level. For subjects at the Sahlgrenska Academy the crowding out effect is not significant at the $10 \%$ level, but the effect of adding a charity option is significant at the 10\% level ( $p$-value=0.052).
} 
the $5 \%$ level, both according to the non-parametric test ( $p$-value $=0.043$ ) and the logistic regression analysis ( $p$-value $=0.044$ ). The effect of the charity option is significant at the $10 \%$ level both according to the non-parametric test ( $p$-value=0.094) and the logistic regression analysis $(p$-value $=0.094)$.

In the experiment subjects were asked to motivate their decision about undergoing the health examination to become a blood donor. We read these motivations to see if they were consistent with the idea that (particularly women) saw the offering of money as degrading the meaning of their good deed. No subjects in the SEK 50 payment group explicitly stated the offering of money as a motivation for not becoming a blood donor. However, if the reason for becoming a blood donor is to signal altruism to receive social esteem in line with the model of Bénabou and Tirole (2006), subjects are unlikely to reveal this motivation in the follow-up question.

\section{CONCLUDING REMARKS}

The answer to our question posed in the title seems to be a qualified yes. For women the crowding out hypothesis of Titmuss (1970) receives empirical support in the data, although we should bear in mind that Titmuss's original conjecture was silent about gender. The crowding out effect for women is also sizeable. Introducing a monetary payment reduced the supply of blood donors by almost half. For men we found no significant crowding out effect. Interestingly we also show that the crowding out effect can be alleviated by allowing individuals to donate the payment to charity. Our results have important policy implications. They suggest that the skepticism towards monetary compensation for blood donations seen in many countries is warranted. But our results also suggest that the potential problem of 
introducing monetary payments can be resolved by simply adding an option to donate the payment to charity.

Our results can also be related to the proposed theoretical explanations of crowding out. Frey and Oberholzer-Gee (1997) argue that the introduction of monetary payments may reduce the intrinsic motivation to behave altruistically or perform one's civic duty. This could potentially explain the crowding out effect, but cannot readily explain why the supply of blood donors increases with the charity option. From the perspective of intrinsic motivation theory the treatment with a SEK 50 payment and the treatment with a SEK 50 payment with a charity option should be identical. Even without the charity option the individual is free to donate SEK 50 to charity after the experiment.

Gneezy and Rustichini (2000a,b) argue that crowding out may be caused by incomplete contracts where the introduction of a payment or fine provides information that affects behavior. In their daycare center experiment they argue that parents may initially be uncertain about the consequences of coming late (as this may not be fully specified in the contract). The introduction of a fine may therefore provide information about the penalty for late-coming parents, and this new information may lead to crowding out (if the penalty is less severe than expected before the introduction of the fine). The incomplete contracts explanation, however, does not provide a fully satisfactory explanation of our results. It is difficult to see how the introduction of a charity option could change the information about the contract compared to the treatment with a SEK 50 payment.

The results are consistent with the recent signaling model of crowding out of Bénabou and Tirole (2006), where they assume that individuals engage in civic activities to signal altruism in order to be perceived as good persons by other individuals. ${ }^{19}$ In this model the

${ }^{19}$ Bénabou and Tirole (2003) also in a related paper present an alternative model that can explain why incentives may decrease performance. However, that model is based on 
introduction of a monetary reward may make it more difficult to signal altruism, and thereby cause crowding out. The model can also explain why a charity option may increase the supply of blood donors. A charity option facilitates signaling, and the crowding out effect may therefore be counteracted. In terms of this model the gender difference observed in our experiment suggests that women are more concerned with social esteem than men.

Experiments on gender differences typically find that women are more prosocial than men (see the overviews in Camerer (2003) and Croson and Gneezy (2004)). Eckel and Grossman (1998) for instance found that women donated more than men in a dictator game. They interpreted this as women being less selfish than men. However, an additional reason for giving in dictator games apart from altruism and fairness may be to signal generosity to increase social esteem. This is consistent with a recent study by Dana et al. (2006) that found that $30 \%$ of the subjects preferred a $\$ 9$ outside option rather than playing a $\$ 10$ dictator game as the allocator (if they chose the outside option the receiver never knew that a dictator game was to be played). This suggests the presence of motivations for donations other than altruism or fairness. Andreoni and Vesterlund (2001) compared men and women in a dictator game where the token value of tokens given to the recipient varied. They found that men were more responsive to the token value than women. This is consistent with women being more sensitive towards social esteem, if the social esteem of giving is independent of the token value. In their overview article about gender differences in preferences, Croson and Gneezy (2004) similarly conclude that women are more sensitive to the social context of the experiment than men. However, further work is clearly needed on gender differences between men and women to draw firmer conclusions.

asymmetric information between the principal and the agent about the agent's ability to perform a specific task and is less relevant for activities such as donating blood. 
Finally, some caveats concerning our study should be mentioned. It cannot be ruled out that the gender difference observed in the study is caused by some other factor correlated with gender in the sample. The study was not designed to test for gender differences, and the experimental design was therefore not ideal for testing the influence of gender (e.g. due to the limited sample size and statistical power). It is also unclear to what extent our results can be generalized. Students may not be representative of the entire population. If anything, given the low income of students, one would expect them to be more responsive towards monetary incentives, which would bias the results against the crowding out hypothesis. The students participating in the experiment may also not be representative of the entire student population. Students received two lottery tickets worth SEK 50 (about US \$7) for participating, and it is possible that this led to a selection of subjects responding to monetary incentives. This would also go against finding a crowding out effect. We tried to counteract this effect by recruiting from large classes where the experiment started immediately after the class in order to try and get a large fraction of the class to participate. But ideally the robustness of the results should be tested in larger and more varied samples. A larger sample size would also have been desirable so as to yield greater statistical power and to test a range of different payment sizes.

It was unfortunate that, at the insistence of the ethics committee, we were obliged to tell the subjects that the experiment was about attitudes to blood donation. This may have led to a selection of subjects interested in this topic or contemplating giving blood, and probably explains the relatively high fraction of subjects agreeing to become blood donors. It may also lead to a framing bias, and lead subjects to give answers conditioned by what they ought to respond rather than by what they would respond in the appropriate context without such a frame.

In the experiment we measured the willingness to complete the health examination that is a precondition for donating blood, rather than actual blood donations. However, completing 
the health examination is a strong predictor of actual donations. In general for the Gothenburg county (where our experiment was carried out) $60 \%$ of individuals who complete the health examination donate blood within a year (excluding those not approved as donors). It would have been ideal to follow-up the individuals in the experiment to get data on actual donations. For ethical reasons this was not possible. However, we were able to get data on the fraction of blood donors among all individuals who carried out the health examination at the dates and time intervals that our experiment took place. The majority of this overall sample (75\% of the individuals) came from our study. Out of the overall sample $78 \%$ of the individuals donated blood within a year from the health examination (excluding those not approved as donors). This percentage is substantially higher than for the unselected overall population in the county, suggesting that subjects in our study did not enroll simply to do the health examination, but to become blood donors. 


\section{REFERENCES}

Andreoni, James, and Lise Vesterlund (2001). "Which is the Fair Sex? Gender Differences in Altruism.” Quarterly Journal of Economics, 116, 293-312.

Arrow, Kenneth J. (1972). “Gifts and Exchanges.” Philosophy and Public Affairs 1, 343-362.

Bénabou, Roland, and Jean Tirole (2003). “Intrinsic and Extrinsic Motivation.” Review of Economic Studies, 70, 489-520.

Bénabou, Roland, and Jean Tirole (2006). “Incentives and Prosocial Behavior.” American Economic Review 96, 1652-1678.

Camerer, Colin F. (2003). Behavioral Game Theory: Experiments in Strategic Interaction. Princeton University Press.

Croson, Rachel, and Uri Gneezy (2004). “Gender Differences in Preferences.” Mimeo, University of Chicago.

D’Agostino, Ralph B., Warren Chase, and Albert Belanger (1988). “The Appropriateness of Some Common Procedures for Testing the Equality of Two Independent Binomial Populations.” American Statistician, 42, 198-202. 
Dana, Jason, Daylian Cain, and Robyn Dawes (2006). “What You Don’t Know Won’t Hurt Me: Costly (but Quiet) Exit in Dictator Games.” Organizational Behavior and Human Decision Processes, 100, 193-201.

Deci, Edward L., and Richard M. Ryan (1985). Intrinsic Motivation and Self-Determination in Human Behavior. Plenum Press.

Eckel, Catherine, and Philip J. Grossman (1998). “Are Women Less Selfish Than Men? Evidence from Dictator Experiments.” Economic Journal, 108, 726-735.

Ellingsen, Tore, and Magnus Johannesson (2007). "Pride and Prejudice: The Human Side of Incentive Theory.” Mimeo, Stockholm School of Economics.

Falk, Armin, and Michael Kosfeld. "The Hidden Costs of Control." American Economic Review, 96, 1611-1630.

Fehr, Ernst, and Simon Gächter (2002). “Do Incentive Contracts Undermine Voluntary Cooperation?” Working Paper, University of Zurich.

Fehr, Ernst, and John A. List (2004). "The Hidden Costs and Returns of Incentives: Trust and Trustworthiness Among CEOs.” Journal of the European Economic Association, 2, 743-771.

Fehr, Ernst, and Bettina Rockenbach (2003). "Detrimental Effects of Sanctions on Human Altruism.” Nature, 422, 137-140. 
Frey, Bruno S. (1993). "Motivation as a Limit to Pricing.” Journal of Economic Psychology, $14,635-664$.

Frey, Bruno S. (1994). “How Intrinsic Motivation is Crowded Out and In.” Rationality and Society, 6, 334-352.

Frey, Bruno S., Felix Oberholzer-Gee, and Reiner Eichenberger (1996). "The Old Lady Visits Your Backyard: A Tale of Morals and Markets.” Journal of Political Economy, 104, 12971313.

Frey, Bruno S., and Felix Oberholzer-Gee (1997). “The Cost of Price Incentives: An Empirical Analysis of Motivation Crowding-Out.” American Economic Review, 87, 746-755.

Gneezy, Uri, and Aldo Rustichini (2000). "Pay Enough or Don’t Pay at All.” Quarterly Journal of Economics, 115, 791-810.

Gneezy, Uri, and Aldo Rustichini (2000). “A Fine is a Price.” Journal of Legal Studies, 29, 117.

Ireland, Thomas R., and James V. Koch (1973). “Blood and American Social Attitudes.” In: The Economics of Charity. Institute of Economic Affairs, 1973.

Lepper, Mark R., and David Greene, eds (1978). The Hidden Costs of Reward: New Perspectives on the Psychology of Human Motivation. Erlbaum. 
Seabright, Paul (2004). “Continuous Preferences Can Cause Discontinuous Choices: An Application to the Impact of Incentives on Altruism.” Mimeo, Toulouse University.

Solow, Robert S. (1971). “Blood and Thunder.” Yale Law Journal, 80, 1696-1711.

Titmuss, Richard M. (1970). The Gift Relationship. Allen and Unwin. 


\section{APPENDIX: EXPERIMENTAL INSTRUCTIONS}

The original instructions were in Swedish. This appendix reprints a translation of the question about becoming a blood donor in the three experimental treatments ("No payment”; "SEK 50 payment”, and “SEK 50 payment with charity option”).

\section{Facts about the health examination ("No payment")}

To be able to donate blood in a blood bus or at a hospital it is necessary to first carry out a health examination. The health examination consists of filling out a health declaration and a physical examination by a nurse (who will measure your blood pressure and take a blood test).

The blood test is done to make sure that your blood cannot harm the receiver. The health examination (health declaration and physical examination) takes about 15 minutes. About 30 days after completing the health examination the individual will be notified about whether he/she is suitable as a blood donor.

\section{Question 8}

You will now be given the opportunity to carry out a health examination, which will make it possible for you to become a blood donor. We have hired a bus parked outside which can transport you to the Regional Blood Center, Sahlgrenska University Hospital. The health examination including the transportation will take about 30 minutes. You will of course also be transported back to the School of Economics and Commercial Law if you wish.

Everyone responding yes below will first fill out a health declaration in this room and 
thereafter go with the hired bus to Sahlgrenska University Hospital to measure blood pressure and take a blood test.

Will you do the health examination?

Yes ( )

No ( )

Please motivate why you answered yes or no to the above question (question 8): 


\section{Facts about the health examination ("SEK 50 payment")}

To be able to donate blood in a blood bus or at a hospital it is necessary to first carry out a health examination. The health examination consists of filling out a health declaration and a physical examination by a nurse (who will measure your blood pressure and take a blood test).

The blood test is done to make sure that your blood cannot harm the receiver. The health examination (health declaration and physical examination) takes about 15 minutes. About 30 days after completing the health examination the individual will be notified about whether he/she is suitable as a blood donor.

\section{Question 8}

You will now be given the opportunity to carry out a health examination, which will make it possible for you to become a blood donor. We have hired a bus parked outside which can transport you to the Regional Blood Center, Sahlgrenska University Hospital. The health examination including the transportation will take about 30 minutes. You will of course also be transported back to the School of Economics and Commercial Law if you wish.

If you choose to carry out the health examination you will receive SEK 50 in compensation. The SEK 50 will be paid when we collect the health declaration.

Everyone responding yes below will first fill out a health declaration in this room and thereafter go with the hired bus to Sahlgrenska University Hospital to measure blood pressure and take a blood test. 
Will you do the health examination?

Yes ( ) SEK 50 in compensation

No ( )

Please motivate why you answered yes or no to the above question (question 8): 
Facts about the health examination ("SEK 50 payment with charity option")

To be able to donate blood in a blood bus or at a hospital it is necessary to first carry out a health examination. The health examination consists of filling out a health declaration and a physical examination by a nurse (who will measure your blood pressure and take a blood test).

The blood test is done to make sure that your blood cannot harm the receiver. The health examination (health declaration and physical examination) takes about 15 minutes. About 30 days after completing the health examination the individual will be notified about whether he/she is suitable as a blood donor.

\section{Question 8}

You will now be given the opportunity to carry out a health examination, which will make it possible for you to become a blood donor. We have hired a bus parked outside which can transport you to the Regional Blood Center, Sahlgrenska University Hospital. The health examination including the transportation will take about 30 minutes. You will of course also be transported back to the School of Economics and Commercial Law if you wish.

If you choose to carry out the health examination you can choose between receiving SEK 50 in compensation and donating SEK 50 to the Children's Cancer Foundation. The SEK 50 will be paid when we collect the health declaration; the money that is donated will be immediately put in a collecting box that belongs to the Children’s Cancer Foundation.

Everyone responding yes below will first fill out a health declaration in this room and thereafter go with the hired bus to Sahlgrenska University Hospital to measure blood pressure 
and take a blood test.

Will you do the health examination?

Yes ( ) SEK 50 in compensation

Yes ( ) donate SEK 50 to the Children's Cancer Foundation

No ( )

Please motivate why you answered yes or no to the above question (question 8): 
TABLES

Table 1. Descriptive statistics of the sample.

\begin{tabular}{|l|l|l|l|l|l|l|}
\hline Treatment: & $\begin{array}{l}\text { Number } \\
\text { of } \\
\text { subjects }\end{array}$ & \multicolumn{2}{|c|}{ Gender } & \multicolumn{3}{c|}{ Subject affiliation } \\
\hline & & Men & Women & $\begin{array}{l}\text { Sahlgrenska } \\
\text { Academy }\end{array}$ & $\begin{array}{l}\text { School of } \\
\text { Economics } \\
\text { and } \\
\text { Commercial } \\
\text { Eaculty of }\end{array}$ & Education \\
\hline No payment & 89 & 35 & 54 & 13 & 43 & 33 \\
\hline SEK 50 payment & 85 & 35 & 50 & 8 & 42 & 35 \\
\hline SEK 50 payment or & 88 & 39 & 49 & 13 & 44 & 99 \\
\hline donate to charity & & 109 & 153 & 34 & 129 & \\
\hline Total & 262 & & & & & \\
\hline
\end{tabular}


Table 2. Experimental results: the supply of blood donors in each treatment.

\begin{tabular}{|l|l|l|l|l|l|l|}
\hline Treatment: & \multicolumn{2}{|c|}{ All subjects } & \multicolumn{2}{c|}{ Men } & \multicolumn{2}{c|}{ Women } \\
\hline & Number & $\%$ & Number & $\%$ & Number & $\%$ \\
\hline No payment (1) & $38 / 89$ & 42.70 & $10 / 35$ & 28.57 & $28 / 54$ & 51.85 \\
\hline $\begin{array}{l}\text { SEK 50 payment (2) } \\
\text { charity option (3) }\end{array}$ & $28 / 85$ & 32.94 & $13 / 35$ & 37.14 & $15 / 50$ & 30.00 \\
\hline $\begin{array}{l}\text { Hypotheses tests (p-value } \\
\text { of difference): } *\end{array}$ & $39 / 88$ & 44.32 & $13 / 39$ & 33.33 & $26 / 49$ & 53.06 \\
\hline $\begin{array}{l}\text { Crowding out hypothesis } \\
\text { (treatment 1 versus 2) }\end{array}$ & 0.185 & & & & & \\
\hline $\begin{array}{l}\text { Charity option hypothesis } \\
\text { (treatment 2 versus 3) }\end{array}$ & 0.125 & 0.445 & & 0.024 & \\
\hline
\end{tabular}

* A Pearson chi-square test is used to estimate p-values. 
Table 3. Results of logistic regression analysis on the probability of becoming a blood donor.

\begin{tabular}{|c|c|c|c|c|c|}
\hline Variable & & All subjects & Men & Women & $\beta$ men $=\beta$ women \\
\hline \multirow[t]{2}{*}{ Constant } & $\beta$ (se) & $0.590(0.433)$ & $-0.0003(0.75)$ & $0.499(0.551)$ & \\
\hline & $p$-value & 0.173 & 0.9997 & 0.365 & 0.591 \\
\hline \multirow[t]{3}{*}{ Treatment: no payment* } & $\beta$ (se) & $0.357(0.326)$ & $-0.459(0.557)$ & $0.798(0.428)$ & \\
\hline & $p$-value & 0.274 & 0.410 & 0.062 & 0.074 \\
\hline & marginal effect & 0.085 & -0.092 & 0.198 & \\
\hline \multirow[t]{3}{*}{ Treatment: charity option* } & $\beta$ (se) & $0.442(0.326)$ & $-0.312(0.529)$ & $0.939(0.435)$ & \\
\hline & $p$-value & 0.174 & 0.556 & 0.031 & 0.068 \\
\hline & marginal effect & 0.106 & -0.062 & 0.233 & \\
\hline \multirow{3}{*}{$\begin{array}{l}\text { Subjects: School of } \\
\text { Economics and } \\
\text { Commercial Law** }\end{array}$} & $\beta$ (se) & $-0.977(0.417)$ & $0.027(0.726)$ & $-1.668(0.548)$ & \\
\hline & $p$-value & 0.019 & 0.970 & 0.002 & 0.062 \\
\hline & marginal effect & -0.234 & 0.005 & -0.413 & \\
\hline \multirow{3}{*}{$\begin{array}{l}\text { Subjects: Faculty of } \\
\text { Education** }\end{array}$} & $\beta$ (se) & $-1.526(0.432)$ & $-2.469(1.001)$ & $-1.404(0.539)$ & \\
\hline & $p$-value & $<0.001$ & 0.014 & 0.009 & 0.349 \\
\hline & marginal effect & -0.365 & -0.493 & -0.348 & \\
\hline \multirow[t]{3}{*}{ Gender (1=man) } & $\beta$ (se) & $-0.541(0.276)$ & & & \\
\hline & $p$-value & 0.050 & & & \\
\hline & marginal effect & -0.129 & & & \\
\hline Number of observations & & 262 & 109 & 153 & \\
\hline Chi-square ( $p$-value) & & $20.462(0.001)$ & $18.364(0.001)$ & $17.825(0.001)$ & \\
\hline Log-likelihood & & -166.179 & -59.965 & -96.403 & \\
\hline McFadden Pseudo- $\mathrm{R}^{2}$ & & 0.058 & 0.133 & 0.085 & \\
\hline \% individual prediction & & 63.74 & 64.22 & 61.44 & \\
\hline
\end{tabular}

*Baseline category: SEK 50 payment treatment. **Baseline category: Sahlgrenska Academy. 
FIGURES

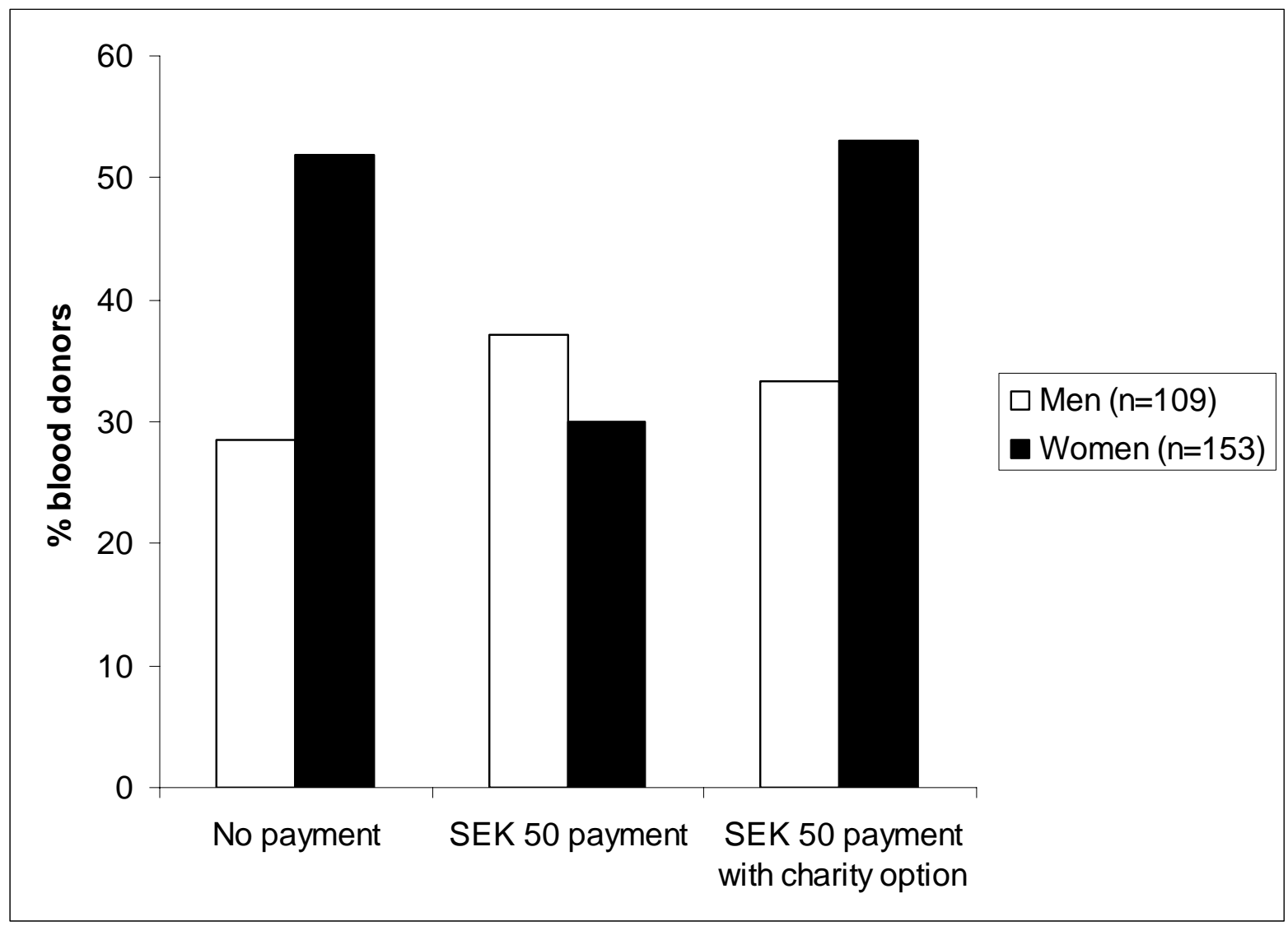

Figure 1. The supply of blood donors among men and women in the three experimental treatments. 


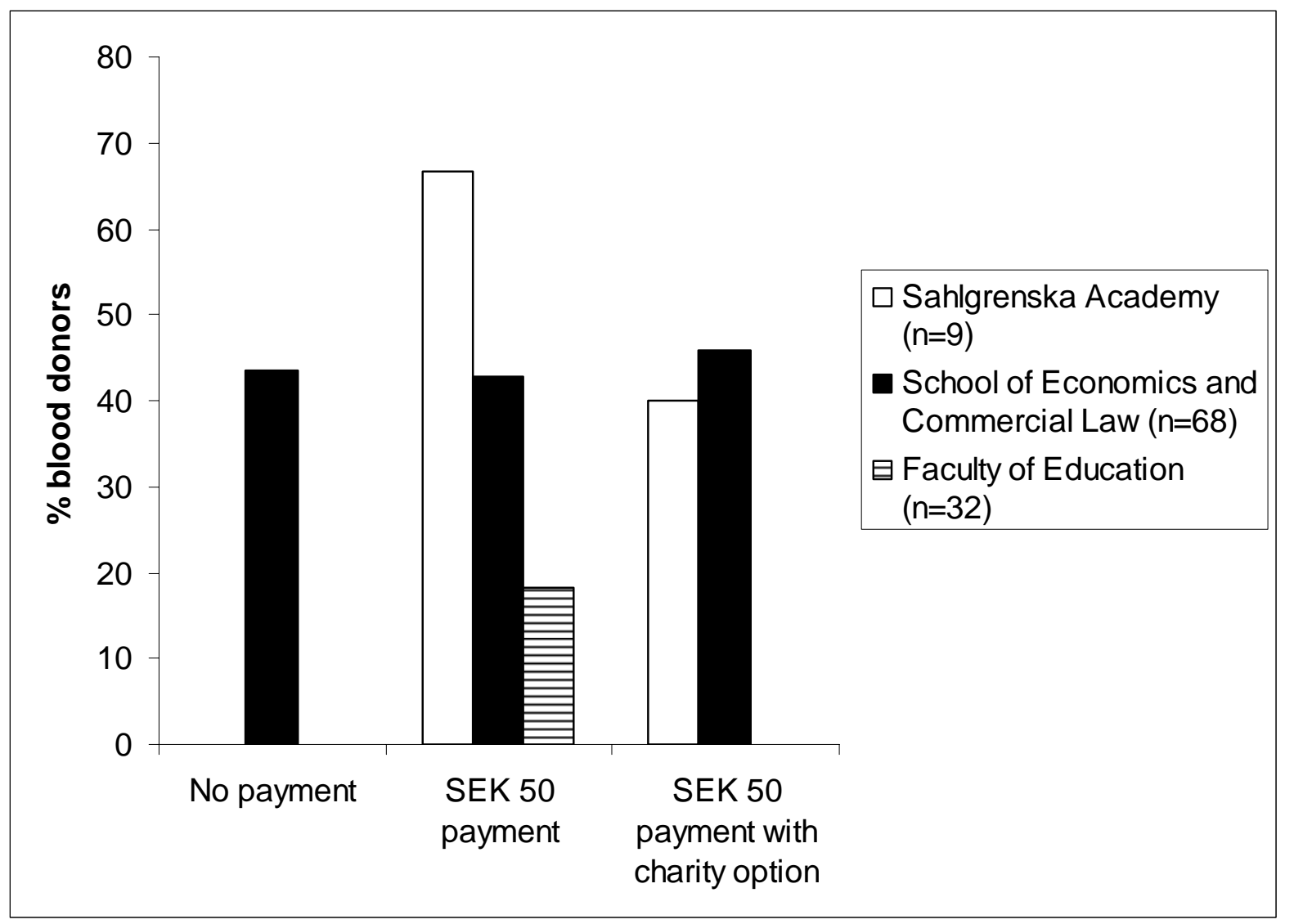

Figure 2. The supply of blood donors among men for different subject affiliations (no bar implies $0 \%$ blood donors in that treatment/subject group). 


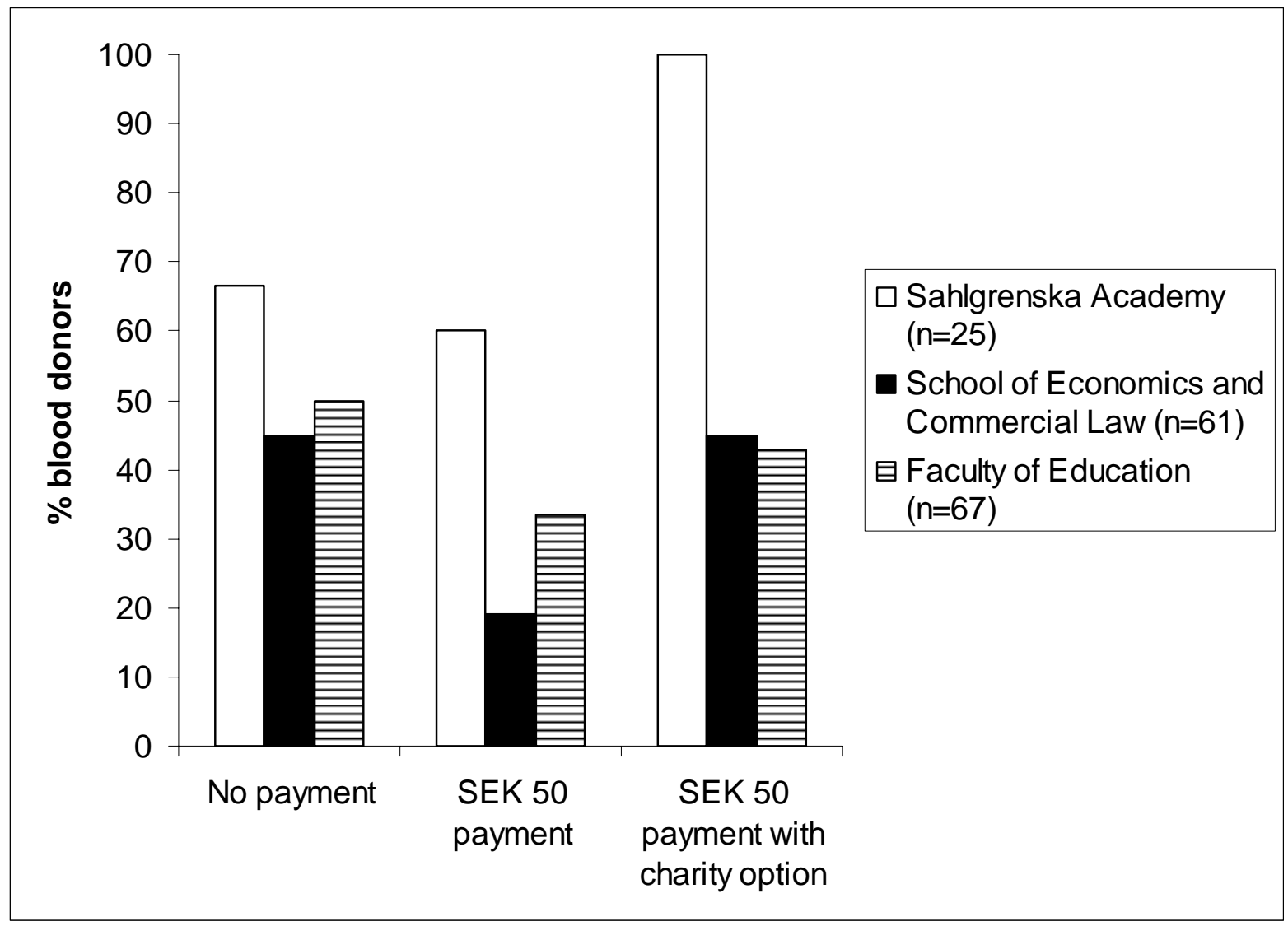

Figure 3. The supply of blood donors among women for different subject affiliations. 